\title{
Zur Blutalkalescenzbestimmung.
}

Von

S. Salaskin und Z. Pupkin.

(Aus dem physiologisch-chemischen Laboratorium der medizinischen Hochschule für Frauen zu St. Petersburg.)

(Der Redaktion zugegangen am 23. Juni 1904.)

Die Anwendung der Methoden der physikalischen Chemie zur Bestimmung der Blutreaktion (Höber, Friedenthal, Fränkel, Farkas) hat erwiesen, daß in bezug auf seinen Gehalt an H- resp. OH-Ionen das Blut dem Wasser ähnelt, d. h. daß es in diesem Sinne neutral reagiert oder, anders gesagt, weder aktive Acidität noch aktive Alkalescenz, welche durch Überwiegen der einen oder der anderen Ionen bedingt sind, besitzt. Außer dieser aktiven Reaktion kommt jedoch für den Organismus auch noch die potentielle Reaktion in Betracht, d. h. die Fähigkeit, bei verändertem Verlauf des Stoffwechsels die Blutreaktion unverändert zu erhalten. Dem Blute kommen bekanntlich einerseits Säurebindungsvermögen, andererseits Basenkapaziät zu; diese doppelte Fähigkeit ist zweifellos für die Aufrechterhaltung einer konstanten aktiven Blutreaktion von großer Wichtigkeit; deshalb besitzen die Methoden, mit deren Hilfe man diese potentiellen Reaktionen bestimmen kann, entschieden einen gewissen Wert, denn sie dienen als Maß für die Tätigkeit des Organismus, gegen Verhältnisse, welche für sein Gedeihen unzuträglich sind, anzukämpfen. In dieser Beziehung ist die Bestimmung des Säurebindungsvermögens wichtiger als wie diejenige der Basenkapazität, denn eines Überschusses an Alkalien entbürdet sich das Blut sehr leicht, indem es sie mit dem Harn ausscheidet. Leider sind jedoch alle Verfahren, welche zur Bestimmung des Säurebindungsvermögens des Blutes vorgeschlagen worden sind, äußerst ungenau; hiervon kann man sich sofort überzeugen, wenn man die Zahlen- 
werte, welche verschiedene Beobachter nach ein und derselben Methode erhalten haben, auch nur oberflächlich durchmustert. Die Bestimmung der potentiellen Alkalescenz (oder des Säurebindungsvermögens) nach der Titriermethode stößt auf so bedeutende Schwierigkeiten, daß die Idee von Salkowski, ${ }^{1}$ ) dieselbe zu ersetzen durch die Bestimmung der Fähigkeit des Blutes, Ammoniak aus Ammoniaksalzen zu verdrängen und auf diese Weise die Menge der nicht gesättigten alkalischen Affinitäten zu bestimmen, als höchst scharfsinnig und treffend anzuerkennen ist, nur weist die Form, in welcher Salkowski diese Bestimmung vorzunehmen vorschlägt, bedeutende Mängel auf. Die Methode von Salkowski erfordert sehr viel Zeit (5-6 Tage) und dennoch kann man nicht sicher sein, daß die Ammoniakausscheidung ihr Ende erreicht hat. Deshalb hat Salaskin, ${ }^{2}$ ) sich streng an die Idee von Salkowski haltend, der Methode nur eine andere Form verliehen. Die Modifikation besteht darin, daß das Blut resp. Serum mit Ammoniumsulfat unter die Glocke des Apparates von Nencki und Zaleski gestellt und im Vacuum bei einer Temperatur des von außen einwirkenden Wasserbades von $40^{\circ} \mathrm{C}$. destilliert wird. Die Bestimmung dauert ca. 2 Stunden. Diese Modifikation hat Salaskin in seiner in Gemeinschaft mit $\mathrm{E}$. Kowalevsky veröffentlichten Arbeit beschrieben, wobei auch bemerkt war, daß diese Methode von S. Salaskin in Gemeinschaft mit Pupkin weiter ausgearbeitet wird. Vorliegende Veröffentlichung stellt das Ergebnis dieser gemeinschaftlichen Untersuchung dar.

Es mußte vor allem über die Bedeutung der verschiedenen Faktoren und über die Fehlerquellen Klarheit geschaffen werden. Bei diesen Untersuchungen stellte sich folgendes heraus:

1. Die Dissociation des $\left(\mathrm{NH}_{4}\right)_{2} \mathrm{SO}_{4}$ resp. $\mathrm{NH}_{4} \mathrm{Cl}$ in wässeriger Lösung ist im Vacuum bei $40^{\circ}$ eine ganz unbedeutende. Bei Salzmengen von $0,2-2,0 \mathrm{~g}$ und Wassermengen von $10-100 \mathrm{ccm}$ mußten zur Neutralisation von $1 / 10 \mathrm{H}_{2} \mathrm{SO}_{4} 0,2-0,4 \mathrm{ccm}{ }^{1 / 20} \mathrm{KOH}$ angewandt werden. Die Destillation wurde bis zur Trockene fortgesetzt.

1) Zentralblatt f. d. med. Wissensch. 1898, S. 913.

2) Diese Zeitschrift, Bd. XXXV, S. 553. 
2. Bei den erwähnten Versuchsbedingungen (Vacuum, $40^{\circ}$, Destillation bis zur Trockene) verdrängen $\mathrm{KOH}, \mathrm{NaOH}$, $\mathrm{NaHCO}_{3}$ und $\mathrm{Na}_{2} \mathrm{CO}_{3}$ aus $\left(\mathrm{NH}_{4}\right)_{2} \mathrm{SO}_{4}$ resp. $\mathrm{NH}_{4} \mathrm{Cl}$ eine äquivalente Menge $\mathrm{NH}_{3}$.

3. $\mathrm{Na}_{2} \mathrm{HPO}_{4}$ verdrängt aus $\left(\mathrm{NH}_{4}\right)_{2} \mathrm{SO}_{4}$ resp. $\mathrm{NH}_{4} \mathrm{Cl} \mathrm{Am}-$ moniak ungefähr in solcher Menge, welche genügend 'ist, um die Hälfte des (in 15\% iger Lösung) angewandten $\mathrm{Na}_{2} \mathrm{HPO}_{4}$ in $\mathrm{NaH}_{2} \mathrm{PO}_{4}$ umzuwandeln. $\mathrm{NaH}_{2} \mathrm{PO}_{4}$ verdrängt Ammoniak aus Ammoniaksalzen nicht.

4. Nimmt man zu dem Versuche $\mathrm{NaOH}$ und $\mathrm{NaH}_{2} \mathrm{PO}_{4}$, so wird aus Ammoniaksalzen etwas weniger Ammoniak verdrängt, als bei der Berechnung auf die angewandte $\mathrm{NaOH}-\mathrm{Menge}$ zu erwarten wäre, es dient also ein Teil des $\mathrm{NaOH}$ zur Bildung von $\mathrm{Na}_{2} \mathrm{HPO}_{4}$.

5. Eiweißstoffe (Fibrinogen, Eierglobulin und Serumalbumin) verdrängen Ammoniak zum Teil aus Ammoniaksalzen, jedoch in so geringem Grade, daß dieser Prozeß durchaus nicht als Fehlerquelle dienen kann.

6. Versetzung des Blutes mit Wasser kann das Ergebnis der Bestimmung in gewissem Grade beeinflussen. Wir lassen hier einige Zahlenangaben folgen, welche wir unseren zahlreichen diesbezüglichen Untersuchungen entnommen haben.

Differenz beim Titrieren: $15 \mathrm{ccm}$ defibrin. Hundeblut $+\quad 0,5 \mathrm{~g}\left(\mathrm{NH}_{4}\right)_{2} \mathrm{SO}_{4} \quad 16,3 \mathrm{ccm} \mathrm{1/30} \mathrm{N.} \mathrm{KOH}$

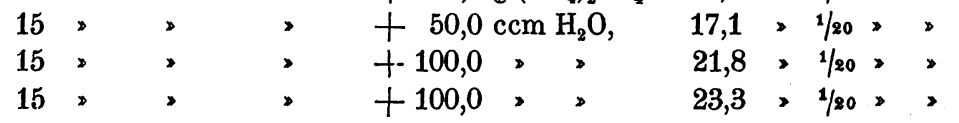

Destilliert wurde stets bis zur Trockene. Sämtliche derartige Bestimmungen ergaben ein ganz identisches Resultat: je mehr Wasser wir hinzufügten, um so größer war die Differenz beim Titrieren, wobei parallele Bestimmungen bei gleichem Wasserzusatz gewöhnlich nicht ganz übereinstimmten.

Der Gang der Analyse war folgender: Es wurden $10 \mathrm{ccm}$ Blut resp. Serum unter die trockene Glocke des Apparates von Nencki und Zaleski gebracht, ihnen $0,5-1 \mathrm{~g}$ fein gepulvertes $\left(\mathrm{NH}_{4}\right)_{2} \mathrm{SO}_{4}$ (letzteres muß neutrale Reaktion zeigen) hinzugefügt, in die Rezipienten wurden je $10 \mathrm{ccm} 1 / 10 \mathrm{~N} . \mathrm{H}_{2} \mathrm{SO}_{4}$ gegossen; nachdem alle Teile des Apparates vereinigt waren, wurde 
etzterer unter zeitweisem Schütteln der Glocke $1 / 2-1$ Stunde stehen gelassen; sodann wurde zur Bestimmung geschritten, welche ebenso wie bei der Ammoniakbestimmung ausgeführt wird; die Destillation wurde bis zur Trockene fortgesetzt.

Es folgen die Zahlenwerte, welche bei Anwendung oben erwähnter Methodik für das Blut resp. Blutserum von Pferd, Ochs und Hund erhalten worden sind.

\section{Defibriniertes Pferdeblut. ${ }^{1}$ )}

Differenz beim Titrieren:

1. $10 \mathrm{ccm}$ Blut $+0,25 \mathrm{~g}\left(\mathrm{NH}_{4}\right)_{2} \mathrm{SO}_{4}$

$10>>+0,25$,
$10>>$
$10>>$
$10>>$
$10>$
$10>$
$10>$

$12,4 \mathrm{~cm} 1 / 20 \mathrm{~N} . \mathrm{KOH}$

$\left.\begin{array}{l}12,4>1 / 20>> \\ 12,4>1 / 20>>\end{array}\right\} 0,244 \% \mathrm{NaOH}$

2. $10>>+0,25 »$ >

$12,8>1 / 20>>0,252 \%$,

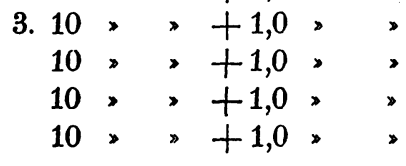

$\left.\begin{array}{r}15,4>1 / 20,> \\ 15,5>1 / 20,> \\ 15,4>1 / 80,> \\ 15,4>1 / 20>>\end{array}\right\} 0,285 \%$

Im Mittel 0,260\% $\mathrm{NaOH}$

Pferdeblutserum.

Differenz beim Titrieren:

$\left.\begin{array}{ll}\text { 1. } 10 \mathrm{ccmSerum}+0,25 \mathrm{~g}\left(\mathrm{NH}_{4}\right)_{2} \mathrm{SO}_{4} & \begin{array}{l}10,2 \mathrm{ccm}^{1 / 20} \mathrm{~N} . \mathrm{KOH} \\ 10,\end{array}, 10,1,1 / 20,\end{array}\right\} 0,201 \% \mathrm{NaOH}$

2. $10>,+1,0$, ,

$10, \quad+1,0$,

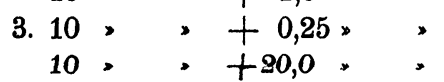

$10,1 \times 1 / 80>>0,186^{\circ}$

$10,1,1 / 20,>\} 0,186 \%$

$10,0 \times 1 / 20, \times$

$10,0 \times 1 / 00 \times>\} 0,185 \%$

Im Mittel $0,191 \% \mathrm{NaOH}$

Defibriniertes 0chsenblut.

Differenz beim Titrieren:

1. $10 \mathrm{ccm} \mathrm{Blut}+1,0 \mathrm{~g}\left(\mathrm{NH}_{4}\right)_{2} \mathrm{SO}_{4}$

$10>+1,0>>$

2. $10>+1,0>$,

$10>>+1,0>$.

3. $10>+0,5$,

$10>+0,5$, ?

$\left.\begin{array}{l}14,0 \mathrm{ccm} 1 / 80 \mathrm{~N} . \mathrm{KOH} \\ 13,8>1 / 20>>\end{array}\right\} 0,298 \% \mathrm{NaOH}$

$11,7,1 / 20 ;$,

$\left.\begin{array}{r}11,7 \geqslant 1 / 20>> \\ 11,5>1 / 20>>\end{array}\right\} 0,247 \%$,

$11,2,1 / 20 \times$,

$11,2 \times 1 / 20>,\} 0,245 \%$.

Im Mittel $0,263 \% \mathrm{NaOH}$

1) Die Ätzkalilösung war nicht genau 1/20 normal und ihre Konzentration war nicht in allen Versuchen ein und dieselbe, deshalb wurde die Berechnung der Alkalescenz in Prozent $\mathrm{NaOH}$ mit Hilfe eines entsprechenden Koeffizienten ausgeführt. Die mit ein und derselben $\mathbf{N}$ bezeichneten Analysen sind Parallelbestimmungen. 
Ochsenblutserum.

Differenz beim Titrieren:

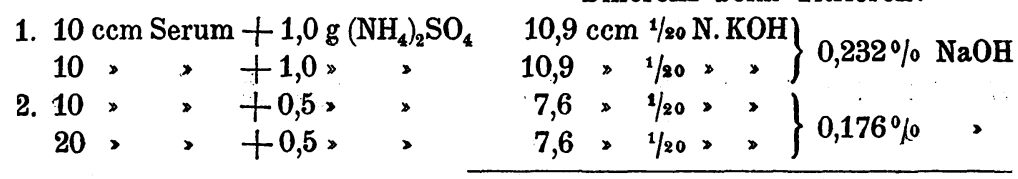

Im Mittel $0,204 \% \mathrm{NaOH}$

Defibriniertes Hundeblut.

Differenz beim Titrieren:

1. $10 \mathrm{ccm} \mathrm{Blut}+1,5 \mathrm{ccm} \mathrm{NH}_{4} \mathrm{Gl}$

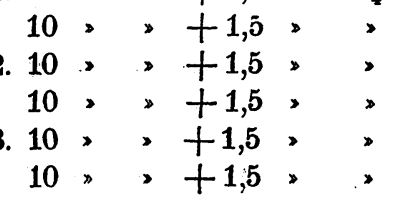
$\left.\begin{array}{l}14,2 \mathrm{ccm} 1 / 20 \mathrm{~N} . \mathrm{KOH} \\ 14,2,1 / 20,\end{array}\right\} 0,291 \% \mathrm{NaOH}$ $12,1,1 / 20>>\}$ $12,1,1 / 20 ;,>0,251 \%$. $\begin{aligned} & 12,7>1 / 20>> \\ & 12,7>1 / 20>>\end{aligned} 0,260 \%$,

Im Mittel $0,267 \% \mathrm{NaOH}$ Hundeblutserum.

Differenz beim Titrieren:

1. $15 \mathrm{ccm}$ Serum $+0,5 \mathrm{~g}\left(\mathrm{NH}_{4}\right)_{2} \mathrm{SO} 、 \quad 9,5 \mathrm{ccm}^{1} / 20 \mathrm{~N} . \mathrm{KOH}=0,129 \% \mathrm{NaOH}$ 2. $15,>+0,5,>8,8 \times 1 / 20,>=0,120 \%$,

Auf Grund alles oben Gesagten meinen wir behaupten zu dürfen, daß diese Methode mit Recht neben den anderen zum Zwecke der Blutalkalescenzbestimmung vorgeschlagenen Methoden einen Platz behaupten kann. Für klinische Zwecke ist sie aus dem Grunde nicht gut anwendbar, weil zur Untersuchung etwa $10 \mathrm{ccm}$ Blut erforderlich sind; jedoch glauben wir, daß bei Untersuchungsverfahren, welche, wie das mit dem Alkalimeter von Engel, nur 0,05 ccm Blul erfordern, die Fehlerquelle eine so große ist, daß wohl kaum von einem wissenschaftlichen Werte der erzielten Resultate die Rede sein kann. 